\title{
Parental Attitudes About a Pregnancy Predict Birth Weight in a Low-Income Population
}

\author{
Robert D. Keeley, MD, MSPH \\ Alison Birchard, $\mathrm{MPH}^{2}$ \\ Perry Dickinson, $M D^{1}$ \\ Jobn Steiner, $M D, M P H^{3}$ \\ L. Miriam Dickinson, $P b D^{1}$ \\ Susan Rymer, $B A^{4}$ \\ Blake Palmer, $\mathrm{BS}^{5}$ \\ Torri Derback, $B S^{4}$ \\ Allison Kempe, $M D, M P H^{6,7}$
}

'Department of Family Medicine, University of Colorado Health Sciences Center, Aurora, Colo

${ }^{2}$ Boulder County Department of Public Health, Boulder, Colo

${ }^{3}$ Division of General Internal Medicine, University of Colorado Health Sciences Center, Aurora, Colo

${ }^{4}$ University of Colorado School of Medicine, Aurora, Colo

${ }^{5}$ University of Oklahoma School of Medicine, Oklahoma City, Okla

${ }^{6}$ Department of Pediatrics, University of Colorado Health Sciences Center, Aurora, Colo

${ }^{7}$ The Children's Hospital, Denver, Colo

Conflict of interest: Robert Keeley is also the director of the Community Health Research Initiative, a small, not-for-profit organization dedicated to improving bealth quality for the underinsured and uninsured, which supported this project.

\section{CORRESPONDING AUTHOR}

Robert Keeley UCHSC Fitzsimmons

PO Box 6508 Campus Box F-496

Aurora, CO 80045

Robert.Keeley@UCHSC.edu

\begin{abstract}
BACKGROUND Low birth weight remains the primary cause of neonatal morbidity and mortality in the United States. We examined whether maternal happiness about a pregnancy, in addition to her report of the father's happiness, predicts birth weight and risk for low birth weight $(<2,500 \mathrm{~g})$.

METHODS In this prospective cohort study, the mother's report of her and her partner's happiness about the pregnancy was measured before 21 weeks' gestation on a scale from 1 to10 (1 to 3 unhappy, 4 to 7 ambivalent, or 8 to 10 happy). "Mother reports partner happier" occurred when the mother perceived the father's happiness score at least 5 points greater than her own. Information on birth weights and maternal sociodemographic, medical, and psychosocial factors were obtained from surveys and medical records.
\end{abstract}

RESULTS Of 162 live births, 9 were low birth weight (5.6\%). Compared with women who reported happiness with the pregnancy, risk for low birth weight was greater when the mother reported partner happier about the pregnancy (relative risk 10.0, 95\% confidence interval, 3.1-32.4). This predictor of birth weight remained significant in multivariate linear regression analyses (coefficient $=-472 \mathrm{~g}, \mathrm{SE}=171 \mathrm{~g}, P=.007$ ) after adjustment for other known predictors of birth weight.

CONCLUSIONS Maternal report of greater partner happiness about a pregnancy is associated with birth weight and appears to define low- and high-risk subgroups for low birth weight in a low-income population. Further study in larger samples is needed to confirm our findings and to assess whether maternal report of greater partner happiness is itself a modifiable factor or is a marker for other factors that might be modified with targeted interventions.

Ann Fam Med 2004;2:145-149. DOI: 10.1370/afm.57.

\section{INTRODUCTION}

L ow birth weight remains the primary cause of neonatal morbidity and mortality in the United States, ${ }^{1,2}$ and low-birth-weight infants survivlogical disabilities. ${ }^{3}$ The prevalence of low birth weight has risen steadily during the last 17 years $^{4}$ from $6.5 \%$ to $7.8 \%$ in 2002 . Section 16-10a of Healtby People 2010 recommends decreasing the rate of low birth weight to $5.0 \%$ by $2010 .^{4}$

A variety of socioeconomic, medical, and psychosocial factors are known to increase the risk of low birth weight, ${ }^{5-19}$ but prevention programs aimed at primarily high-risk subgroups have been largely ineffective. ${ }^{2}$ We chose to study a low-risk subgroup because, although known risk factors are sometimes strongly predictive of poor birth outcomes, most low-birth-weight infants are born to women without these traditional risk factors. ${ }^{12,20}$

Maternal intendedness ${ }^{9,18,19}$ and attitude toward a pregnancy ${ }^{14,19,21,22}$ may predict low birth weight and birth weight. Most pregnancy intended- 
ness and all attitude studies are based upon retrospective assessments, however, and their clinical relevance is uncertain. ${ }^{14,19,22-24}$ Maternal perceptions of partner intendedness and happiness toward the pregnancy may also represent modifiable predictors of pregnancy outcomes. ${ }^{13,14,19,21,25}$ Our study goals were to test whether the mother's reports of her own and the father's happiness about a pregnancy measured before 21 weeks' estimated gestational age predict birth weight and the risk of low birth weight.

\section{METHODS}

\section{Study Design}

This prospective cohort study was situated at a community health center in a Western city, population 80,000 , serving a mostly low-income white, predominately Latina population. All women older than 17 years initiating care before 21 weeks' estimated gestational age were invited to participate. The sample included $43 \%$ of women initiating prenatal care at the clinic and giving birth between the fall of 2000 and the winter of 2001 and $33 \%$ of the low-birth-weight infants from the clinic during that period. The overall clinic rate of low birth weight in 2000 was $7.3 \%$, similar to $7.5 \%$ county and $7.6 \%$ national rates. Bilingual female research assistants questioned participants at the first prenatal visit with a portion of the 1995 National Survey of Family Growth (NSFG) ${ }^{26}$ and administered the Personality Assessment Inventory (PAI). ${ }^{27,28}$ Women younger than 18 years were omitted because the PAI and intendedness/attitude portions of the NSFG might not be valid in this age-group. ${ }^{25,29}$

\section{Measures}

\section{National Survey for Family Growth}

NSFG, a periodic fertility survey, is reliable and valid in both English and Spanish and recommended by the Institute of Medicine ${ }^{30}$ for assessing a variety of pregnancy-related variables. We selected questions assessing pregnancy planning and intendedness, happiness concerning the pregnancy, the participant's perception of her partner's intendedness and happiness, and sociodemographic variables.

\section{Personality Assessment Inventory}

PAI, a self-administered objective test of personality and psychopathology, ${ }^{27,28}$ is compatible with the Diagnostic and Statistical Manual of Mental Disorder Version IV ${ }^{31}$ and is valid and reliable in English and Spanish. Anxiety, depressive disorders, drug problems, somatic concerns, and stress levels were obtained from PAI scales.

\section{Variable Definitions}

\section{Major Outcome Variables}

The major outcomes were birth weight and low birth weight rate. Major predictor variables were maternal happiness and intendedness and relative perceived partner happiness. Each participant was asked to describe, on a scale from 1 to 10 , how she felt about her pregnancy at the moment of discovery. The scale was adapted for the fifth administration of the NSFG, with scores 1 to 3 signifying unhappiness, 4 to 7 ambivalence, and 8 to 10 happiness. Each participant also rated her perception of her partner's happiness. ${ }^{30,32,33}$

Eight NSFG questions defined pregnancy planning and intendedness and perceived partner's intendedness. Intendedness was dichotomized as unintendedintended, as unwanted-wanted, and as a couple's combined unwanted scale (either parent unwanted vs other combinations). ${ }^{30}$ A couple intendedness scale was derived to reflect agreement between partners.

Relative perceived partner happiness is the mother's estimation of the difference between the parents' happiness levels. Recognizing that a 5-point difference is equivalent to a 1-category crossover, such as from unhappy to happy, ${ }^{32}$ we subdivided the responses into 3 meaningful categories by subtracting the maternal from the perceived partner happiness score to cover the ranges: -9 to $-5,-4$ to +4 , and +5 to +9 . The first ( -9 to -5$)$ category represents a situation in which the pregnant woman perceives herself happier than her partner about the pregnancy. In the middle category she perceives similar happiness levels concerning the pregnancy, and in the third ( +5 to +9$)$ category the mother reports the partner happier.

\section{Potential Confounding Variables}

Variables that might confound the relationship of interest were assessed from previous publications. ${ }^{5-20,30}$ Sociodemographic variables obtained with the NSFG included place of birth, educational attainment, relationship, dominant language, age, education, and race/ ethnicity. Insurance status was obtained from the clinic database.

Medical and physical variables derived from the NSFG and medical records included late entry to prenatal care, adequacy of prenatal care, ${ }^{33}$ maternal medical problems, parity, maternal weight at enrollment, alcohol and tobacco use during pregnancy, history of previous low-birth-weight infant, and history of previous spontaneous abortion or demise. Adequacy of prenatal care is stratified into 5 categories from "no care" to "intensive" based upon timing of initiation of prenatal care, estimated gestational age at delivery, and number of clinic visits. ${ }^{33}$ Smoking was ascertained using 
Table 1. Sociodemographic Characteristics of Women with Normal and Low-Birth-Weight Infants, and Relative Risks for Low Birth Weight

\begin{tabular}{|c|c|c|c|}
\hline Characteristic & $\begin{array}{c}\% \text { Normal Birth } \\
\text { Weight }(\geq 2,500 \mathrm{~g}) \\
(\mathrm{n}=153)\end{array}$ & $\begin{array}{c}\% \text { Low Birth Weight } \\
(<2,500 \mathrm{~g}) \\
(\mathrm{n}=9)\end{array}$ & $\begin{array}{l}\text { Relative Risk for } \\
\text { Low Birth } \\
\text { Weight }(95 \% \mathrm{CI})\end{array}$ \\
\hline Hispanic & 74.5 & 66.7 & $0.70(0.16-2.86)$ \\
\hline English dominant & 43.8 & 88.9 & $10.27(1.25-84.1)^{*}$ \\
\hline Age, mean y $( \pm S D)$ & $23.9( \pm 4.8)$ & $24.6( \pm 6.7)$ & $P=.72$ \\
\hline Young maternal age & 63.4 & 77.7 & $2.02(0.41-10.1)$ \\
\hline Parents married or live together & 89.9 & 44.4 & $0.21(.054-0.83)^{*}$ \\
\hline Education < 12 y & 54.9 & 55.6 & $1.03(0.3-4.0)$ \\
\hline Smoking & 21.6 & 55.6 & $4.54(1.16-17.89)^{*}$ \\
\hline History of fetal loss & 16.3 & 22.2 & $1.46(0.3-7.5)$ \\
\hline Low maternal enrollment weight & 35.9 & 66.7 & $3.6(0.9-14.8)$ \\
\hline Late gestational age at enrollment & 37.3 & 44.4 & $1.34(0.3-5.2)$ \\
\hline Parity, mean No. ( $\pm S D)$ & $3.1( \pm 0.9)$ & $3.1( \pm 1.1)$ & $P=.72$ \\
\hline Maternal unwanted pregnancy & 13.1 & 22.2 & $1.9(0.4-9.8)$ \\
\hline Unhappy or ambivalent mother & 25.5 & 88.9 & $23.4(2.83-193.0)^{*}$ \\
\hline $\begin{array}{l}\text { Maternal report of greater } \\
\text { partner happiness }\end{array}$ & 5.9 & 44.4 & $12.8(2.92-56.0)^{*}$ \\
\hline \multicolumn{4}{|l|}{$\begin{array}{l}\mathrm{Cl}=\text { confidence interval. } \\
* P<.05\end{array}$} \\
\hline \multicolumn{4}{|c|}{$\begin{array}{l}\text { Note: Categories for variables follow-ethnicity (Hispanic, non-Hispanic white }+3 \text { other); dominant language (Spanish, English); maternal age (mean } \pm \text { SD and } 18-24 \text { y } \\
\text { vs } 25+y) \text {; marital status (married/cohabiting vs single/dating); education }(<12 \mathrm{y}, \geq 12 \mathrm{y}) \text {; smoking (yes, no); history of fetal loss (spontaneous abortion or fetal demise); } \\
\text { maternal enrollment weight }(<132 \mathrm{lb} \text { vs } \geq 132 \mathrm{lb}) ; \text { gestational age at enrollment }(\geq 14 \text { wk vs }<14 \text { wk); parity (number of live births); maternal unwanted pregnancy } \\
\text { (unwanted, mistimed }+ \text { intended); maternal happiness status (unhappy }+ \text { ambivalent, happy); mother reports partner happier (mother reports father happiness } 5+\text { points } \\
\text { higher than her own happiness); risk ratios for maternal planning; previous low-birth-weight infant; maternal medical problems (gestational diabetes, preexisting hyperten- } \\
\text { sion or preeclampsia, renal problems, and anemia); and psychosocial variables omitted because of cells with } 0 \text { or } 1 .\end{array}$} \\
\hline
\end{tabular}

survey and chart review because of underreporting of socially undesirable traits. ${ }^{34}$

We assessed psychosocial variables potentially associated with poor outcomes with the PAI. Somatic concerns, anxiety, depressive disorders, stress, and drug problems were analyzed as continuous and as dichotomous variables using cut points of mild, moderate, and severe elevations. ${ }^{28}$

\section{Statistical Analyses}

We compared study participants having live births with participants experiencing fetal loss and who were lost to follow-up. Continuity-adjusted chi-square tests were used to determine where there was a significant association between low birth weight and each risk factor, then unadjusted risk ratios for low birth weight were computed (Table 1).

A multivariate linear regression model ${ }^{35-37}$ allowed us to estimate the influence of maternal happiness and maternal report of greater partner happiness on infant birth weight after adjustment for the potential confounders previously listed (Table 2). Using Pearson correlation coefficients, we tested sociodemographic, medical, psychosocial, and pregnancy planning and intendedness/attitude variables for association with birth weight. Because of the relatively small sample size, covariates were tested in preliminary models, and all those with $P<.25$ were retained in the final model. We used the statistical software package SAS 8.2 (SAS Institute, Inc, Cary, NC).

\section{RESULTS}

One-hundred eighty women were invited to participate, 2 declined, and 178 (95.5\%) joined the study. There were 7 spontaneous abortions, 1 fetal death, and 8 were lost to follow up. The mean birth weight from the other 162 participants was 3,306 $\pm 508 \mathrm{~g}$ (range $1,630$ to $4,904 \mathrm{~g})$, and $9(5.6 \%)$ infants were low birth weight.

The 8 women lost to follow-up did not differ from those with known live births by measures of attitude, intendedness, or other study factors, whereas women experiencing fetal loss were more likely to report somatic complaints and a history of previous fetal loss $(P=.04)$. Of 20 women with medical problems during the pregnancy, most were minor, such as mild anemia, although 4 experienced gestational diabetes.

Language and birthplace were collinear $(R=0.81$, $P<.001)$, and we retained language. In univariate analyses, parents married or living together, tobacco abuse, dominant language English, maternal unhappiness or 
Table 2. Adjusted Predictors of Birth Weight

\begin{tabular}{lcl}
\hline & $\begin{array}{c}\text { Multiple Linear } \\
\text { Regression } \\
\text { Coefficient } \\
\text { g (SE) }\end{array}$ & P Value \\
\hline Intercept & $3.323(114)$ & .0001 \\
Spanish-speaking mother & $187(72)$ & .01 \\
Young maternal age & $-164(76)$ & .03 \\
Previous low-birth-weight infant & $-455(146)$ & .002 \\
Parents married or live together & $113(85)$ & .19 \\
Low maternal enrollment weight & $-267(74)$ & .0004 \\
Maternal medical problems & $201(108)$ & .06 \\
Maternal anxiety & $271(121)$ & .027 \\
Maternal report of greater & $-472(171)$ & .007 \\
partner happiness & & \\
\hline
\end{tabular}

Note: All variables obtained during the study, including maternal planning status and psychosocial variables depression, anxiety, stress, somatic concerns, and drug problems, were screened for possible inclusion in the multivariate linear model.

Final multiple linear regression model: dependent variable birth weight was analyzed as a continuous variable with adjustment for the following variables: dominant language (English or Spanish); age (18-24 y vs $25+y)$; previous low-birth-weight infant (yes, no); relationship (single or dating vs married or living together); low maternal enrollment weight (less than $132 \mathrm{lb}$ vs $132+\mathrm{lb}$ ); maternal anxiety (none to mild, moderate or greater); and mother reports partner happier (yes, no).

ambivalence about the pregnancy, and mother reports partner happier were significantly associated with low birth weight (Table 1 ).

In the final multivariate linear regression model with birth weight (grams) as the outcome (Table 2), dominant language Spanish, moderate to severe anxiety, and maternal medical problems $(P=.06)$ were associated with larger infants. Younger maternal age, history of previous low-birth-weight infant, low maternal weight at enrollment, and maternal report of greater partner happiness (coefficient $=-472 \mathrm{~g}, \mathrm{SE}=171 \mathrm{~g}, P=.007$ ) were associated with decreased birth weight. Although there was a trend toward association with lower birth weight $(P=.06)$, maternal unhappiness or ambivalence was not significant in a multivariate model. There were no associations between maternal planning or intendedness or perceived paternal intendedness and birth outcomes.

This model explained 29\% of the variability in birth weight $\left(R^{2}=0.29\right)$. Potential intermediary factors, including alcohol or tobacco abuse, maternal weight gain, anxiety, depression, drug problems, somatization, and stress, ${ }^{38}$ did not explain the influence of perceived attitudes on birth weight.

\section{DISCUSSION}

This birth outcome study is the first of which we are aware to incorporate mother's perceptions of the father's intendedness and happiness and to confirm prospectively that maternal unhappiness about a preg- nancy is associated with low birth weight. ${ }^{14,19}$ The study identifies maternal report of greater partner happiness and possibly maternal ambivalence about a pregnancy as risk factors. Consistent with previous studies, planning and maternal or paternal intendedness were not related to birth outcomes, ${ }^{22}$ and Spanish-speaking mothers had larger infants than Englishspeaking mothers. ${ }^{39}$ The summary maternal medical problems scale predicted larger infants, probably secondary to occurrence of gestational diabetes in 4 study participants.

Strengths of the present study include the prospective, consecutive design. Generalizability is increased by English- and Spanish-speaking Latina subgroups but is decreased by the low-income study population, as well as by the exclusion of young teenagers, women seeking care late in their pregnancy, and those receiving no prenatal care. Eight patients lost to follow-up could have experienced birth outcomes affecting the results. Maternal and partner reports of the partners' intendedness and happiness might not correlate. The small sample size and the low rate of low birth weight preclude adjusted risk ratios, so results require additional confirmation.

Interventions targeted at traditional high-risk groups may have achieved minimal success because the associated causal mechanisms of low birth weight are biological (young teenagers) or intractable and socially mediated (drug addiction or no prenatal care). ${ }^{20}$ Such interventions have not been targeted at subgroups of low-risk women because of the prohibitive costs and lack of sensitive predictors of poor outcomes. As has been shown in several previous studies, those most likely to benefit from targeted interventions are often not those who access such programs. ${ }^{40,41}$ If asking a woman about pregnancy attitudes can be shown to be predictive of adverse birth weight outcomes in other populations, and if the attitudinal risk factor is modifiable without causing untoward effects through labeling someone high risk, a strategy of focusing new intervention strategies in low-risk women may be effective.

To read or post commentaries in response to this article, see it online at http://www.annfammed.org/cgi/content/full/2/2/145.

Key words: Birth weight; infant low birth weight; paternal behavior; pregnancy, unwanted; maternal-fetal relations

Submitted August 19, 2002; submitted, revised, May 2, 2003; accepted May 20, 2003.

This paper was previously presented at the NRSA Trainees Research Conference, Washington, DC, June 22, 2002; and at the North American Primary Research Conference, New Orleans, La, November 18, 2002.

Funding support: This work was supported in part by a National Research Service Award, funded by the Bureau of Health Professions (a division of the Health Resources and Services Administration), 
Grant \# 5 T32 HP 10006, and by a grant from the Community Health Research Initiative, Longmont, Colo.

Acknowledgments: We would like to thank the Primary Care Fellowship at the University of Colorado for reviewing multiple versions of the paper and Tillman Farley, MD, Medical Director of Plan de Salud del Valle, Inc, for supporting and guiding the project.

\section{References}

1. McCormick MC. The contribution of low birthweight to infant mortality and childhood morbidity. New Engl J Med. 1985;312:82-90.

2. Stevens-Simon C, Orleans M. Low-birthweight prevention programs: the enigma of failure. Birth. 1999:184-191.

3. Hack M, Klein NK, Taylor HG. Long-term developmental outcomes of low birth weight infants. Future Child. 1995;5:176-196.

4. US Department of Health and Human Services. Increase the proportion of pregnancies that are intended. In: Healthy People 2010 Maclean, VA: International Medical Publishing, Inc; 2001:9-1.

5. Ruijter I, Miller JM Jr. Evaluation of low birthweight in African Americans. J Natl Med Assoc. 1999;91:663-667.

6. Gortzak-Uzan L, Hallak M, Press F, Katz M, Shoham-Vardi I. Teenage pregnancy: risk factors for adverse perinatal outcome. J Matern Fetal Med. 2001;10:393-397

7. Bird ST, Chandra A, Bennett T, Harvey SM. Beyond marital status: relationship type and duration and the risk of low birth weight. Fam Plann Perspect. 2000;32:281-287.

8. Parker D, Schoendorf KC, Kiely JL. Associations between measures of socioeconomic status and low birth weight, small for gestational age, and preterm delivery in the United States. Ann Epidemiol. 1994;4: 271-278.

9. Sharma R, Synkewecz C, Raggio T, Mattison DR. Intermediate variables as determinants of adverse pregnancy outcome in high-risk inner-city populations. J Natl Med Assoc. 1994;86:857-860.

10. Lekea-Karanika V, Tzoumaka-Bakoula C, Matsaniotis NS. Sociodemographic determinants of low birthweight in Greece: a population study. Paediatr Perinat Epidemiol. 1999;13:65-77.

11. Copper RL, Goldenberg RL, Das A, et al. The preterm prediction study: maternal stress is associated with spontaneous preterm birth at less than thirty-five weeks' gestation. National Institute of Child Health and Human Development Maternal-Fetal Medicine Units Network. Am J Obstet Gynecol. 1996;175:1286-1292.

12. Orr ST, James SA, Miller CA, et al. Psychosocial stressors and low birth weight in an urban population. Am J Prev Med. 1996;12:459-466.

13. Hoffman S, Hatch MC. Stress, social support and pregnancy outcome: a reassessment based on recent research. Paediatr Perinat Epidemiol. 1996:10:385-405.

14. Sable MR, Wilkinson DS. Impact of perceived stress, major life events and pregnancy attitudes on low birth weight. Fam Plann Perspect. 2000;32:288-294

15. Paarlberg KM, Vingerhoets AJ, Passchier J, Dekker GA, Heinen AG, van Geijn HP. Psychosocial predictors of low birthweight: a prospec tive study. Br J Obstet Gynaecol. 1999; 106:834-841.

16. Pritchard CW, Teo PY. Preterm birth, low birthweight and the stressfulness of the household role for pregnant women. Soc Sci Med. 1994;30:89-96.

17. Kelly RH, Russo J, Katon W. Somatic complaints among pregnant women cared for in obstetrics: normal pregnancy or depressive and anxiety symptom amplification revisited? Gen Hosp Psychiatry. 2001;23:107-113.

18. Cartwright A. Unintended pregnancies that lead to babies. Soc Sci Med. 1988; 27:249-254.
19. Sable MR, Spencer JC, Stockbauer JW, Schramm WF, Howell V, Herman AA. Pregnancy wantedness and adverse pregnancy outcomes: differences by race and Medicaid status. Fam Plann Perspect. 1997;29:76-81.

20. Wise PH. Confronting racial disparities in infant mortality: reconciling science and politics. Am J Prev Med. 1993;9(6 Suppl):7-16.

21. Fischer RC, Stanford JB, Jameson P, DeWitt MJ. Exploring the concepts of intended, planned, and wanted pregnancy. J Fam Pract. 1999;48:117-122

22. Sable MR. Pregnancy intentions may not be a useful measure for research on maternal and child health outcomes. Fam Plann Perspect. 1999;31:249-250

23. Joyce TJ, Grossman M. Pregnancy wantedness and the early initiation of prenatal care. Demography. 1990;27:1-17.

24. Stanford JB, Hobbs R, Jameson P, DeWitt MJ, Fischer RC. Defining dimensions of pregnancy intendedness. Matern Child Health J. 2000:4:183-189.

25. Cowley C, Farley T. Adolescent girls' attitudes toward pregnancy: the importance of asking what the boyfriend wants. J Fam Pract. 2001:50:603-607.

26. Petersen R, Moos MK. Defining and measuring unintended pregnancy: issues and concerns. Womens Health Issues. 1997;7:234-240.

27. Morey LC. Personality Assessment Inventory Professional Manual. Odessa, Fla: Psychological Assessment Resources, Inc; 1991.

28. Morey LC. An Interpretative Guide to the Personality Assessment Inventory. Odessa, Fla: Psychological Assessment Resources, Inc; 1996.

29. Rubin V, East P. Adolescents' pregnancy intentions. J Adolesc Health. $1999 ; 24: 313-320$

30. Brown S, Eisenbert L. The Best Intentions: Unintended Pregnancy and the Well-Being of Children and Families. Washington, DC: National Academy Press; 1995:364

31. American Psychiatric Association. Diagnostic and Statistical Manual of Mental Disorders. 4th ed. Washington, DC: American Psychiatric Association; 1994.

32. Zabin LS, Huggins GR, Emerson MR, Cullins VE. Partner effects on a woman's intention to conceive: 'not with this partner'. Fam Plann Perspect. 2000;32:39-45.

33. Abma JC, Chandra A, Mosher WD, Peterson LS, Piccinino LJ. Fertility, family planning, and women's health: new data from the 1995 National Survey of Family Growth. Vital Health Stat 23. 1997:1-114.

34. Kotelchuck M. An evaluation of the Kessner Adequacy of Prenatal Care Index and a proposed Adequacy of Prenatal Care Utilization Index. Am J Public Health. 1994;84:1414-1420.

35. Dreyfuss ML, Msamanga Gl, Spiegelman D, et al. Determinants of low birth weight among HIV-infected pregnant women in Tanzania. Am J Clin Nutrition. 2001;74:814-826.

36. Pickett KE, Abrams B, Selvin S. Maternal height, pregnancy weight gain, and birth weight. Am J Human Biology. 2000;12:682-687.

37. Wang S, Zuckerman B, Pearson C, Kaufman G. Maternal cigarette smoking, metabolic gene polymorphism, and infant birth weight. JAMA. 2002;287:195-202

38. Sheehan TJ. Stress and low birth weight: a structural modeling approach using real life stressors. Soc Sci Med. 1998;47:1503-1512.

39. Fuentes-Afflick E, Hessol NA, Perez-Stable EJ. Maternal birthplace, ethnicity, and low birth weight in California. Arch Pediatr Adolesc Med. 1998; 152:1105-1112.

40. Nutting PA, Barrick JE, Logue SC. The impact of a maternal and child health care program on the quality of prenatal care: an analysis of risk group. J Community Health. 1979;4:267-279.

41. Kempe A, Renfrew B, Barrow J, Cherry D, Levinson A, Steiner JF. The first two years of a state child health insurance plan - who are we reaching? Pediatrics. 2003;111:735-740. 